\section{THE BRITISH SYNTHETIC COLOUR INDUSTRY IN WAR TIME.}

THE lecture delivered to the Society of Arts by Mr. C. M. Whitaker in December last merits a more than passing notice as illustrating the difficulties in the way of British dye producers during the war period and the manner in which a commendable degree of success has been obtained in coping with the dye shortage. It deserves to be more generally known that even before the war British firms were already opposing a resolute front to German competition. These firms not only issued patterncards and circulars comparable in style with those sent out by their foreign rivals, but they also dealt with the difficulty of language by printing these manuals of instruction in the principal European tongues. Even in 1906 these instructions had been furnished by the pioneer firm of Read Holliday and Sons, Ltd., in all these languages, ind also in Japanese. Very early in the development of the colour industry this firm had acquired the Schutzenberger and Lalande patent for dyeing indigo by the modern scientific process with hydrosulphite, and even to-day the older dyers sometimes refer to this method of indigo dyeing as the "Holliday" vat.

The lecturer pointed out from his own personal knowledge that the practice of sending out practical dyers to assist the firm's clientele of dye-users in their application of the colouring matters is not exclusively a German procedure. The above-mentioned firm and its successors, British Dyes, Ltd., have afforded their customers this expert assistance for more than thirty years.

At the outbreak of war the British dye industry was in the bands of four or five firms, who together controlled a capital not greatly exceeding half a million sterling, and the problem confronting this group of industrialists was how to replace the former German import of dyes having an annual value of about 1,800,oool. Even in peace times such a problem would be incapable of immediate solution, but taking into account the distractions of war, the results obtained in the last two years are distinctly encouraging. The vulnerable point in the British position was not, however, that of lack of capital, but rather the bad habit which had arisen of buying from abroad intermediate products which could with comparatively little expert knowledge be converted into finished dyes. An additional handicap arising from this cause was the shortage of chemists having the necessary works experience. Attention is being concentrated on these two vital points. The two leading firms, British Dyes, Ltd., and Messrs. Levinstein, Ltd., have taken into their employment a large number of college-trained chemists, some of whom are exercising their talent for research on the essential intermediates, while others are acquiring works experience in the supervision of industrial processes and in the handling of men.

It is impossible for those untrained in organic chemistry to have any correct perception of the amount of preliminary work which precedes the production of a coal-tar dye. The complete manufacture of an ordinary synthetic black may involve twenty-one distinct chemical operations. Other modern products require even more processes. The British dye-firms certainly deserve full credit for their success in coping with the vitally urg $-n t$ requirements of the Allied Governments in equipment colours. One British firm alone furnished the military authorities with $145,000 \mathrm{lb}$ of wool khaki dyes in the fateful month of December, I915, when Army requirements were increasing to an enormous extent. This supply of wool khaki dyes has been maintained, together with prodigious amounts of cotton and linen khaki colours. The armies of our
Italian and Russian Allies have also been largely supplied from British sources. The appearance of the uniforms of soldiers returning on leave is the best testimonial to the fastness of British-made khaki dyes, showing that these colours can withstand the severest war conditions.

In the valuable discussion which followed the lecture the points of interest raised were the question of the multiplicity of names for the same dye and the possibility of simplification in this respect, the German monopoly of bromine, and the relations of the dye-producing industry and teaching institutions.

G. T. Morgan.

\section{THE ROTATION OF THE MOON.1}

$A \mathrm{~N}$ interesting résumé of the progress of our knowA ledge of the moon's rotation, together with a considerable amount of original work, is given in the memoir before us. The author recalls the remarkable control which the earth exerts on the rotation; the line joining the poles of the moon's equator and orbit always passes through the pole of the ecliptie, which lies between them, $1^{\frac{1}{2}}{ }^{\circ}$ from the first, $5^{\frac{1}{4}}{ }^{\circ}$ from the second; both poles revolve round the pole of the ecliptic in 18.6 years. The earth's action has also forced the period of rotation to coincide with that of revolution; the existence of this action is still in evidence from the fact that all secular and longperiod terms in the moon's revolution have their counterpart in the rotation; for example, the secular acceleraition in longitude has not the effect of making us gradually see a different hemisphere.

Much attention has been given of late years to the " physical libration," especially the annual term, which is considerably the largest. Different determinations of its coefficient show a surprisingly large range; the largest value is that of $M$. Puiseux, $19 \cdot 1$, derived from forty Paris photographs covering a period of fifteen years; the other values range from $5 \cdot 7^{\prime}$ to $\mathrm{r} \cdot \mathrm{o}^{\prime}$. We have to divide these figures by 220 to obtain the apparent shift seen from the earth. This gives $\mathbf{5}^{\cdot \mathbf{2}^{\prime \prime}}$ for the Puiseux value; it does not appear that the numerous meridian observations of the crater Mösting A will permit of so large a value.

In studying the problem mathematically, the author makes use of some metkods introduced by MM. Zinner and Charlier, which have appeared in earlier Meddelanden. He denotes the three principal moments of inertia of the moon by A, B, C. A is about the diameter pointing towards the earth, and $C$ about the axis of rotation. The three ratios $(C-A) / A,(C-B) / B$, $(\mathrm{B}-\mathrm{A}) / \mathrm{A}$, are denoted by $k_{1}, k_{2}, k_{3}$. It is shown that stability demands that $\mathrm{B}$ be greater than $\mathrm{A}$, i.e. the moon's equator is elongated towards the earth; if $k_{1}, k_{2}$ have different signs, $\mathrm{C}$ lies between $\mathrm{A}$ and $\mathrm{B}$, and the rotation is unstable. It is shown that $k_{1}, k_{2}$ may be either both positive or both negative; in the first case C, B, A are in descending order of magnitude, in the second case $\mathrm{B}, \mathrm{A}, \mathrm{C}$; the latter would involve rotation about the longest axis, which is interesting as a theoretical possibility, but it is shown later not to be the actual case. Hence $k_{1}, k_{2}$ are both positive. $k_{1}$ is stated to be about 0.000627 ; the values of $k_{3}$ corresponding with the physical libration coefficients of Franz, Hayn, and Puiseux are 0.000314 , 0.000157 , and 0.001178 respectively. The last value makes $k_{2}$ negative, and therefore indicates unstable motion, another reason for concluding that the Puiseux coefficient is too high. However, it is shown that controlled rotation may exist, even when the conditions of stability are not satisfied.

1 "Uber die Rotation des Mondes." Von Axel Jönsson. Meddelanden ôf Lund Observatory, ser. ii., No. $x_{5}$. (Lund; C. W. K. Gleerup, 1917.) 
The suggestion has been made that the moon may not be a perfectly rigid body, but may have sensible change of shape under the varying strains; also that the interior may be partly fluid; the final chapter of the memoir discusses the changes in the equations of motion to which these hypotheses give rise, but does not express any opinion as to their tenability. The preceding chapter gives the numerical calculation of a large number of coefficients, using Brown's expressions for the moon's co-ordinates, and different assumptions for the values of $k_{1}, k_{2}, k_{3}$.

A. C. D. C.

\section{ADAPTATION AND DISEASE.'}

THE time has come to bring before biologists in general the contributions of medical research of the last quarter of a century to the study of evolution. The fact of evolution all thinking minds accept, but as to how evolution has been, and is being, brought about is a very different matter. The fight truly centres upon the cause or causes of variation-whether the tendency to vary is something inherent in living matter, numerous variations presenting themselves through this inherent tendency, of which those that are best fitted for their environment alone survive, or whether it is primarily and essentially brought about by forces acting from without upon a relatively labile living matter: whether, that is, variation is inherent, proceeding from within, or acquired, proceeding from without.

But this basal problem has been largely neglected by the biologists, the fight all these years waging round the secondary problem of the transmission of acquired properties to the offspring. Herbert Spencer made this transmission of acquirements one of his "principles." Weismann violently ${ }^{2}$ opposed the doctrine, carrying with him latter-day biologists, until Mr. Bateson, replete with his studies upon Mendelism, reaches the antipodal suggestion that when a new property manifests itself in any individual of any species, it is impossible to regard it as an acquirement: it is not new, but its manifestation is due to loss of properties already possessed. Evolution, like a squid, progresses backwards, what appears to be a new property is on the contrary primeval. Prof. Bateson's address on Heredity at the International Medical Congress in London in 1913, and his Presidential address at Melbourne in 19I4, were quoted in extenso. That which to outward seeming is the simplest form of life is verily in constitution the most marvellously complex : the higher forms of life are the lower.

The truth seemed to be that valuable and fascinating as are the studies for the establishment and amplification of Mendel's law, that law deals only with the interplay of allelomorphs, with the combinations and permutations of positive and negative unit properties possessed by the species. It only establishes the extent of variation possible within the boundaries of the species. But no amount of interplay of properties already possessed by the species will result in the production of individuals which are outside the species.

Sir Ray Lankester recently laid down that the one fallacy in all Lamarckian doctrine was that adopted by Herbert Spencer, namely, what he termed "direct adaptation." There is really no such thing. The supposed mysterious property of direct adaptation is always due to survival by selection of organisms which varied in many directions.

1 Abstracts of four Croonian Lectures delivered at the Royal College of Physicians on June 14, T9, 2r, and 26, by Prof. J. G. Adami, F.R.S., Temporary I,ient.-Colonel C A.M.C.

2 Sir F.. Ray Lankester has in the British Medical Journal taken exception to the use of this word ; the author agrees that "vigorously" better exprcsses his meaning.

NO. 2494, VOL. 99]
Now if there be one fact that is constantly being impressed upon the student of immunity and the workers in pathogenic bacteriology, it is that direct adaptation, i.e., specific modification in response to specific alteration in environment (within limits which he would lay down) is one of the basal phenomena of living matter. It seems useful, therefore, to marshal in order the data bearing upon these matters as they present themselves to those engaged in medical research.

Problems of this nature are a priori most likely to be solved by experiments upon the very simplest, and again upon the most complex forms of life. For problems of adaptation and heredity the bacteria possess the supreme advantages of rapid reproduction coupled (according to our present knowledge, or want of knowledge) with a complete absence of the disturbing influence of sex and conjugation. Certain biologists are unwilling to regard the products of asexual binary division as true generations. One very distinguished biologist had said that a long cultivation of a bacterial growth is "one continuous individual." This is an impossible position. The very idea of individual connotes independent, or potentially independent, existence. We might with equal logic, basing ourselves on the continuity of the germplasm, declare that all living beings constitute one continuous individual.

\section{Adaptation in the Bacteria and the Evolution of the Infectious Diseases.}

It is absurd to expand the Batesonian hypothesis and imagine that whenever man became man he acquired the germs of all bodily ills, and that the purely human ailments were already there. Some diseases, like tuberculosis, have been with us from the remotest historical times, and even from prehistorical, as witness the late Sir Armaud Ruffer's studies in palæopathology upon mummies of early dynasties, and the recognition of caries and pyorrhœea in permian fishes and tertiary three-toed horses. This is only to be expected. The bacteria are among the earliest of all forms of life. Drew, from his studies of the calcareous ooze of the Florida lagoons, showed that a dentrifying bacillus caused the deposition of chalk out of sea-water. Walcott has discovered Cyanophyceæ and possible micrococci in the oldest of all sedimentary rocks, the Algonkian.

But this does not mean that all orders of pathogenic bacteria and microbes have always been with us. Zymotic phenomena must run parallel with geological. The vast majority of fossils are remains of species and genera which have passed away, but certain species, and, indeed, certain genera, have existed unchanged through countless ages to the present day. The brachiopod Lingula of the Cambrian rocks is to be found to-day living buried in the sand between the tide-marks in the Tropics. The pearly Nautilus, Limulus, Ceratodus, and Anaspides have remained apparently unaltered for extraordinarily long periods of geological time.

The same would seem to be true with respect to zymotic diseases and their causative agents. Many of the plagues and epidemics mentioned by early writers are unrecognisable to-day. The tritest example of a disease which has come and gone is the malignant "sweating sickness," which, first noted in 1485 , was last heard of in $155 \mathrm{I}$. As regards diseases still with us, whatever view be taken regarding the origin of syphilis, it is certain that this was unknown in Egypt and in Rome at the time of Galen. Diphtheria and cholera, both with absolutely characteristic symptoms, were unknown in Europe until the beginning of the nineteenth century. Even if these 